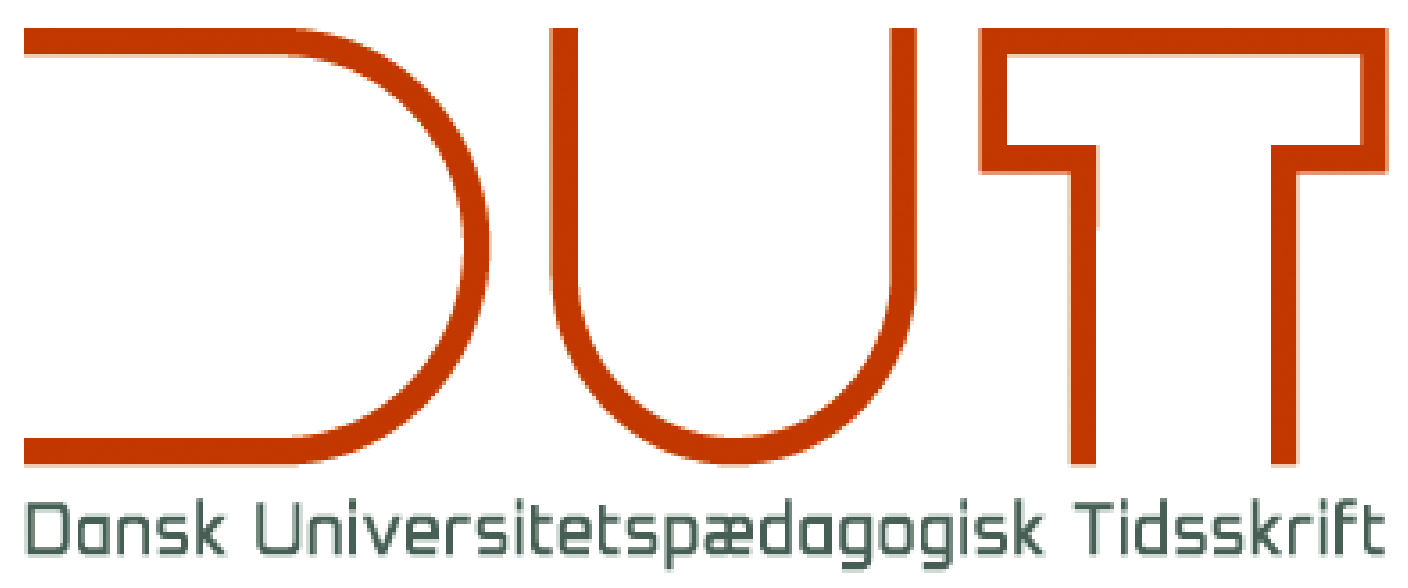

Læringsrum

Årgang 14 nr. 27 / 2019

Titel

Sensing the Same Space - Spatial Understanding and Engagement in Higher Education

Forfattere

Sidetal

Jyri Lindén, Mikko Kanninen, Reijo Kupiainen, Johanna Annala

83-97

Udgivet af

Dansk Universitetspædagogisk Netværk, DUN

URL

> http://dun-net.dk/

Betingelser for brug af denne artikel

(c) Copyright
Denne artikel er omfattet af ophavsretsloven, og der må citeres fra den. Følgende betingelser skal dog være opfyldt:

- Citatet skal være i overensstemmelse med "god skik"

- Der må kun citeres „i det omfang, som betinges af formålet“

- Ophavsmanden til teksten skal krediteres, og kilden skal angives ift. ovenstående bibliografiske oplysninger.

DUT og artiklens forfatter 


\title{
Sensing the Same Space - Spatial Understanding and Engagement in Higher Education
}

\author{
Jyri Lindén ${ }^{a, 1}$, Mikko Kanninen ${ }^{b}$, Reijo Kupiainenc, Johanna Annala ${ }^{a}$ \\ ${ }^{a}$ Faculty of Education and Culture, Tampere University, Finland, bFaculty of Information Technology and \\ Communication Sciences, The Communication Sciences Unit, Tampere University, Finland, 'Faculty of \\ Education and Culture, Tampere University, Finland, Faculty of Education and Lifelong Learning, Norwe-

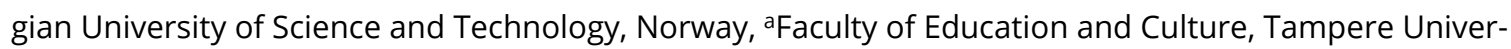 \\ sity, Finland
}

Research article, peer-reviewed

\begin{abstract}
The aim of this theoretically oriented review is to examine the role of space and spatial thinking in the changing teaching and learning environments in higher education. The starting point is that educational space is not a pre-set institution or only a physical space but a social construction. As such, space is a crucial element in the learning process and student engagement.

In the paper, basic concepts of educational space and spatiality are discussed. The complexity of the relations between spatial understanding and student engagement is demonstrated by referring to a specific drama and theatre course as a case example. The case was a joint master-level course between two European universities (in UK and Finland) where multiple online platforms were used.
\end{abstract}

By the means of the learning space in the case, we discuss the nexus of spaces, comprising a dynamic spatial plurality across the learning environments. Blurring boundaries between formal and informal spaces seems to give room for meaningful and embodied experiences - social, situational and emotional connectedness with students in different places. Formal ICT solutions of digital learning do not automatically pay enough attention to spatial aspects of learning and engagement. Understanding the connections between spatial thinking and the meanings of engagement and senses of belonging brings vital elements to the development of digital learning and learning environments. Parallel with the discussions of the distinctive role of interaction and communication in digital environments, spatial understanding can offer an important contribution to increase understanding of personal meanings of learning. Based on the theoretical reflections of the presented case, bodily experiences of the sense of "sharing a space" appears to interrelate with the feelings of belonging and ownership in learning.

\section{Introduction}

In this article, we highlight and explore the importance of examining and understanding space and spatial factors as vital elements for understanding engagement in current higher education (HE) settings. Our starting point, following key arguments from for example Brooks, Fuller, and Waters (2012) and Middleton (2018), is that educational space is not a pre-

\footnotetext{
${ }^{1}$ Contact: jyri.linden@tuni.fi
} 
set institution or only a physical space but more of a social construction - online and offline, inside and outside the actual campus facilities. In other words, space is not an objective formation but a social experience and a network of relations in which materials, resources, information flows, bodily presence and emplaced activities are important factors constituting a place for learning experiences. As such, space is a crucial element in the learning process.

Widespread access to information sources and the use of communication and mobile technologies are blurring the borders of what it means to study at a university. Students are constantly using personal and shared technological platforms, devices and applications to create spaces that overlap the boundaries of formal and informal learning. Formal learning refers to highly structured learning that happens in courses and classrooms, resulting in grades and certificates, whereas informal learning rests primarily in the hands of the learner and their interests and happens through observation, experiences and conversations in various settings (Dabbagh \& Kitsanta 2012). Historically, university's value and meaning as a formal institution has been based on its relation to knowledge production of academic communities located in specific buildings and campuses. Simultaneously with the increased interest in social learning theories and constructionist approaches to knowledge production, HE institutions are struggling with their role as valued producers and evaluators of scientific knowledge (e.g. Muller 2009; Muller \& Young 2014). In relation to this development, Brooks, Fuller, and Waters $(2012$, p. 1) point out that "the emergence of a knowledge-based economy necessitate[s] an understanding of the plurality of spaces (such as homes, workplaces, international space and cyberspace) within which learning can take place, as well as the 'nontraditional' stages in the life course at which it occurs."

The plurality of spaces challenges HE from several angles. As stated by Jamieson et al (2000), the development of online teaching and learning challenged already 17 years ago the meaning of the on-campus student learning experience. They observe that these changes require institutions and teachers to reconsider the relationship of the physical setting with the learning experience and engagement. The sociocultural understanding of student engagement has traditionally emphasised the importance of small group interactions and the sense of (physical) involvement with the community (Kahn 2014). Additionally, in academic practice, much of the pedagogical development and its steering mechanisms are still based on the separation between distance learning or e-learning and learning in the classroom (e.g. Hassenburg 2009). This division has proven to be inadequate for understanding and developing teaching and learning in HE (Middleton 2018). Simultaneously, academic institutions are faced with a growing number of students who are asking for time-space flexibility to adjust their studies to their off-campus life (see e.g. Mäkinen, Linden \& Annala 2018). Many HE institutions in Europe and elsewhere are trying to balance among the decreasing amount of staff and financial resources, the increasing political demands to produce degrees, and meeting the needs of the new-generation students. In these challenging circumstances, it is becoming more and more important to understand spatial thinking and its relation to learning in $\mathrm{HE}$ institutions when they seek both effective and engaging curricula.

Student engagement and experience have drawn scholars' attention in recent years, which has had several emphases. Some approaches focus more on the student as an individual, emphasising the student's actions, dispositions, motivation and participation; how much the student puts her or his time, energy and resources to studies (e.g. Exeter et al. 2010; Hu \& Kuh 2002; Kuh 2003). Other approaches emphasise the university as a community; how the resources, policy and teaching practices support student involvement and participation (e.g. 
Case 2008; Kahu 2013). The broadest approach to student engagement includes student's lifeworld; the societal framework, health, family and work, that all may support or hindrance engagement into studies and engagement into active citizenship (Kipponen \& Annala 2016; Zepke \& Leach 2010).

Focusing specifically on student engagement perspectives, we argue that understanding the meaning and the processes of spatial factors in different educational settings becomes increasingly important to HE institutions. The greater physical "distance" there is between students and a university, the more essential it becomes to generate a spatial experience of "belonging" to a university community. In this sense, Montello, Grossner, and Janelle (2014, p. 12) conclude that "spatial thinking should become an explicit focus of education, promoting it from a subject of incidental and sporadic treatment in uncoordinated disciplinary lessons into a coherent and fundamental push coordinated across disciplines."

Because of their nature, academic studies with a strong emphasis on physical action or situational practical skills training are regarded as difficult or even impossible to move from traditional classroom environments to alternative learning spaces. One such example is acting, which for centuries has been considered site specific and strongly connected to time, place and physical presence. This starting point is one of the main reasons why we demonstrate the complexity of spatial understanding and student engagement with a case example from drama and theatre. Understanding connections of spatiality and engagement in drama courses will hopefully bring new knowledge to be used in the pedagogical development in other fields as well.

\section{Purpose and Context of the Study}

In this theoretically oriented article (see e.g. Weaver-Hightower 2003; Smith, Killgore, \& Lane 2018), targeting an audience interested in pedagogic development in $\mathrm{HE}$, our aim is to provide a focused and accessible introduction to the roles of space and spatial thinking in the changing teaching and learning environments. We introduce some basic concepts and theoretical considerations of spatial thinking in education and, to contextualise the topic, we reflect the prior research findings and concepts against the experiences from a specific university course in drama and theatre. This course, where multiple online platforms were used, offers an interesting pedagogical setting of the relations between spatial experiences and the understanding of student engagement in a challenging multicultural context.

The course was structured around the telepresence setting, where two lecture rooms from two different European countries were virtually connected together to create an illusion of a one shared space. The goal of this setting was to examine how bodily experiences of for example standing on the same floor would affect the spatial experience and learning processes. By referring to the experiences in this case, our goal is to understand and explore how technological settings could relate to engagement and the formation of a social space and place in HE. We examine 1) the theoretical conceptions of space and place and their connections to student engagement, 2) the telepresence classroom as a nexus of spaces, and 3) learning networks and trajectories. Although the nature of this article is theoretically orient- 
ed, we use some excerpts from the Finnish student interviews to exemplify our notions from the theory ${ }^{2}$.

The course presented as a case, Coriolanus Online (CO), was a joint master-level course between Coventry University (the UK) and the University of Tampere (Finland) as part of the degree programme of acting. The project was arranged in 2016, with 15 students from Tampere and 20 students from Coventry (Kanninen, Syrjä \& Gorman 2016). ${ }^{3}$ They were divided into six groups to work together in both Finnish and English. The students were encouraged to experiment with the technology to test its limitations.

The course focused on exploring the challenges faced by theatre performers when acting in a foreign language and the possibilities to improve students' intercultural skills and nonverbal acting attributes. Acting in a foreign language encourages actors to consciously use the body to communicate meaning and to concentrate on the materiality and the musicality of the text, alongside with the physicality of the voice. This approach can improve articulation, adding energy to the act of speaking. It can also have a positive effect on body awareness (Syrjä 2007). The topic of the course was to explore the text of Coriolanus in both Finnish and English. As the Shakespearian blank verse would be difficult and somewhat foreign even for native English speakers and quite unfamiliar to Finnish students, it was agreed that it would present an equal challenge to all students involved.

Several approaches for enabling rehearsal work were considered while planning the project, and the decision was to use multiple online platforms during the course. At the core of the course, a new kind of shared telepresence space (e.g. Pallant, Mclntyre, \& Stephens 2016) connected two similar classrooms together by using videoconferencing technology. The H.323 wide-band technology was repurposed to operate in conjunction with large-scale rear projections in both spaces. A telepresence rehearsal room consisted of two rooms, one in Tampere and the other in Coventry, with a unified spatial design. The careful use of lighting and directional sound integrated in both spaces gave the student actors the illusion of occupying the same rehearsal area. The fine-tuned cameras and projectors in both spaces allowed the participants to make eye contact with each other, of particular importance in performance. The intention was to create a space that was as close to a traditional rehearsal room as possible. Although the telepresence settings in rehearsing rooms in both universities were the main spaces of formal learning activities, other virtual platforms were used too. Students used Skype to study the script and the verbalisation with their peers. The lectures were broadcast by using Adobe connect virtual conference rooms. All the general information, timetables and formal and non-formal announcements were posted on Facebook.

\section{Social Space and Place}

"Spatial turn" originated from social and human sciences in the 1970s and the 1980s, when space started to gain more scientific interest as an inseparable part of everyday social life and meaning making, not only as a geometric dimension. This "spatial turn" refers to the pro-

\footnotetext{
${ }^{2}$ The interview excerpts are from a study that will be reported elsewhere. For this article, we chose only some citations through which we demonstrate our theoretical and conceptual ideas.

${ }^{3}$ The Coriolanus Online project was documented in a video. The footage is shared on YouTube (https://youtu.be/8gjVIQcYjw8).
} 
cess where the understanding that space is a social product became an evident part of research paradigms outside geographical sciences, where space was instead described not as "given" but constructed, reproduced, and transformed in daily life (Arias 2010). Since then, space and place have been important subjects in several disciplines, such as anthropology, spatial humanities, sociology, human and cultural geography and lately, education. However, it has not reached HE in the same manner as lower levels of education. As Leijon (2016) notes, space and place seem to be under-researched topics in $\mathrm{HE}$, or they have been studied by mostly focusing either on architecture or the design of digital learning environments. Temple $(2008)$ also highlighted the issue. He $(2008,233)$ raised the question of the previous lack of research interest in "how students feel about their place in the institution of which they are temporarily a part: is students' learning perhaps helped by their involvement in the creation of social capital, and their uses of it?" Temple, providing an example of interesting research perspectives, emphasizes the importance of understanding how ideas of community and participatory governance in higher education relate to space and how to support this relation in teaching and learning. By referring to Kuh's and his colleagues earlier work, Temple sees that the connection between physical presence and emotional belonging seems to offer an important background for further spatially oriented educational research.

In relation to our approach here, Temple's more recent article (2018) provides an example of examining the meanings of space and place in relation to the institutional effectiveness of higher education. His focus is mainly in the physical campus environment and how theoretical understanding of place and space could affect also our view on teaching, research, and management in the institutional level. Temple is particularly interested in how spatial perspectives could widen our understanding of the senses of ownership, engagement and belonging as crucial parts of learning in HE. These particular themes are key elements in this paper, but instead of examining the physical HE learning spaces, mostly classrooms and buildings, we want to move our focus into those social settings that are digitally mediated (see Middleton 2018).

In our case example of $\mathrm{CO}$, the relations of students and teachers in two universities, as well as their relations to other spaces outside the universities, constitute the living learning space. It is a kind of a knot in a spatial web that also includes virtual space. Using the virtual telepresence space, the students rehearsed a scene in which Coriolanus was exiled from Rome after treating the citizens with arrogance and disdain. This enabled the students to examine the relationship between politicians and the polis in the digital age. The scene (Act 3, Scene 3) took place in an ancient Roman forum, a public space where citizens met their peers. The setting in the scene itself challenged the students to explore the idea of space and created the link between the content and the meaning of a shared learning space.

Relations between spaces of learning and educational practices are of particular interest here. Different spaces seem to have an enabling and constructive role in the educational practices that are possible in particular settings. This assumption problematises the conceptions of inside (e.g., classroom, university) and outside (e.g., home, community) places and consider spaces as relational sets of practices and as fluxes and flows rather than fixed immobilities and dimensions. As a social phenomenon, space can be studied from different perspectives, for example, as a spatial practice and a representational space (Lefebvre 2007). In this case it is question of representational space where students lived and acted. Lived space is the product of human interactions and does not exist prior to students' identities and their relations (Massey 1994). 
Massey (1994) highlights social space as a plurality, constituted within different relations and connections to other spaces, a sphere where distinct trajectories and meanings coexist. Moreover, space is always under construction (never finished, fixed or clear-cut) because it is a product of relations, which are embedded in different material and embodied practices. Human beings are always making spaces in different relations and practices; they do not just step into a ready-made space. Learning can be considered one of the practices that creates space wherever it happens.

The concept of space is sometimes separated from the concept of place. For Casey (2001), space refers to "the encompassing volumetric void in which things (including human beings) are positioned" (p. 683). On the other hand, place is the arena for our actions - a physically, historically, socially and culturally constructed environment of our lived bodies. However, if we perceive space (as we do in this article), not as a pure dimensionality and void but as a social and lived belonging, the difference between space and place is not so clear. As Malpas (2007) argues, space and place are not separable, but both need to be rethought and investigated in conjunction with each other.

Understanding a socially constructed (learning) space requires paying close attention to the histories and the geographies of the adolescents and the adults entering and working there. A space is made home-like by bodily and perceptual activities where learning interweaves with strands of experiences that come from bodily, practical and perceptual activities (Ingold 2011). From our sociocultural perspective, a human being is always located in a place or moving from one place to another. A place is "integral to the very structure and possibility of experience" (Ingold 2011, p. 32). The self relates to the agency and the identity of the geographic subject, whose body is what links this self to a lived place in its sensible and perceptible features. The landscape is the presented layout of a set of places, not their mere accumulation but their sensuous self-presentation. In this way, subjectivity and identity are given "in and through the structure of place" (Ingold 2011, p. 35) but not vice versa.

The experience of place - and indeed the relation of place and the self - can also be described as "thick" or "thin" (Casey 2001). By thick places, Casey refers to spaces to which human beings have a strong connection, where their personal enrichment can flourish, and they feel the spaces as their own. A thick place is meaningful, embodied and emplaced in activities and movements. Usually, we come to know the new place where we are by moving around and having a grasp of the space. A place becomes familiar and home-like, and we become engaged in the place and the activities in it. "Home" does not refer here to any building but to the sense of belonging that connects a person's self and identity to the place and domesticates different learning resources and networks.

Thick places differ from thin places, which are more virtualised, not embodied and not made a person's own. The existing social platforms and digital applications used in universities may have more features of thin rather than thick places. It has been suggested that one reason for students' disengagement from university life in general might be their exploitation of information and communication technology (ICT), but not in ways that would enhance their engagement in studying or learning (Lea \& Jones 2010). However, social online communities have been noted as enhancing a sense of belonging (Silius et al. 2010; Zhao \& Kuh 2004) and strengthening social contacts, community engagement and learning (Kavanaugh et al., 2005; Minocha 2009). When comparing read-only web systems with the potentials of thick social 
spaces and places, the characteristics of sharing, interacting and influencing are promising qualities for enhancing engagement.

Based on the reflections of students and teachers, the environments of the CO course, particularly the telepresence setting and other virtual tools, seemed to include interesting elements of shared thick place. Students described that their process of getting familiar with the virtual spaces was surprisingly straightforward. Both teachers and students reported of the experiences where the virtual settings (telepresence room, skype sessions and Adobe connect lectures) seemed more enabling than restrictive. One possible explanation of this might be that in the telepresence setting, the creation of shared space was considered a key topic. There were a lot of different activities that focused on the bodily exercises where a shared space was concretely created.

\section{Classroom as Nexus of Spaces}

Referring to Lefebvre's (2007) classic example, Leander, Phillips, and Taylor (2010) make an important distinction among different metaphors of classroom as a space for learning. On one hand, classroom is a "container", a location where studying and learning occur, surrounded by the actual walls. In this container metaphor, the concrete realisation of space is often attached to the way we traditionally perceive learning in classroom settings - with the common power relations, materials, interactions, practices and schedules. Another way of understanding classroom space is to imaginatively strip off the walls and observe the flows of all kinds of energy, trying to view it as a "complex of mobilities" or an "active body" (Leander et al. 2010, p. 332). In this so-called nexus-like perspective, the idea of space relates to things such as materials, resources, information flows, bodily presence and emplaced activities. Emplaced activities refer to bodily movements that constitute the place (Pink \& Hjorth 2012).

What is particularly of interest in the work of Leander and colleagues (2010) is their point of collecting possible reasons for a kind of self-evident role of the container-like metaphor of a classroom as a space for learning. Classrooms have traditionally been considered places where it has been the teachers' responsibility to take care of the organisation, management and discipline of the actions of the students. This view seems to suggest that the classroom space itself creates certain norms and regulations for good and proper actions and relations inside it. Another reason for the persistence of the container-like thinking relates to the work of researchers who have created classroom settings and authentic types of groupings for interventions and ethnographic activities (Leander et al. 2010, p. 332). This has also been the case with the studies on $\mathrm{HE}$, particularly in the research settings that examine different modes of interaction in and outside classrooms (see e.g. Nicol \& Boyle 2003).

In the telepresence space of $\mathrm{CO}$, the classroom setting looked like a traditional one, except that two real-life classrooms were connected together with the teleconferencing system, and the room provided more space for bodily movements. The main task of teachers and technicians was to ensure that the rooms were visually and acoustically alike to enable the physical experience of sharing the space. Interestingly, the bodily experience of shared social space was quite concrete and happened suddenly after the lesson began. A student reflected on his feelings as follows

I was waiting the whole time that hey [...], they are going to jump through that screen here [...], like any moment now [...], they are gonna run and end up here [...] (Finnish student 3, male). 
The space seemed to allow the flow of energy, showing clear elements of the thickness of the space. There were also clear indicators of the "active body" (Leander et al. 2010), when the students performed traditional folk dances together, responding to the other students' body movements on both sides of the screen.

Leander and colleagues (2010) point out "how a particular locale - a classroom, community, town, after school club, or website - is not an isolated container, but positioned in a nexus of relations to other such locales" (p. 336). The authors encourage researchers to try to understand the distinctive features that attract students to spaces. They also ask how we could define and understand the social, situational and emotional connectedness that makes certain places "'affectively charged' for learning and how a perspective on place 'helps us' conceive of engagement for learning" (Leander et al. 2010, p. 336). The CO project offers some possible preliminary answers to these questions, connecting learning in a special affectively charged space, learning trajectories of emplaced and embodied interactions, and learning networks for interpreting Shakespeare in two different cultural settings. In the following sections, we examine these issues in more detail.

\section{Spatiality and Engagement}

Though there is a good selection of articles and books focusing on student engagement, comparatively little research exists on how physical or virtual learning spaces and places affect student engagement (Matthews, Andrews, \& Adams 2011). What we already know is that formal and informal learning spaces may create networks with peers, and such networks can lead to greater engagement in active and collaborative learning. In turn, this process may also facilitate knowledge sharing, professional growth and reciprocity to meet academic and professional challenges (Annala et al. 2012; Matthews et al. 2011). However, according to Kipponen and Annala (2016), students may perceive engagement in a broader way than just concerning formal studies and students' individual qualities and efforts.

In the CO case, Adobe Connect was used for mass lectures, but the students chose to use Skype for more informal one-on-one text rehearsals. Moreover, the students set up a Facebook group for scheduling and "hanging out". Collaborative activities outside the classroom may offer possibilities to engage not only in university studies but also in society and active citizenship in alternative ways (Kipponen \& Annala 2016; Zepke \& Leach 2010). Such potentials became visible in the CO project, too, when the students talked about the global meanings of their course, for example,

[...] if we ever wanna feel one as Europe, art is a beautiful way of reaching that goal (Finnish student 3, male).

The global perspective was highlighted in the students' reflections. They brought up visions of future experiments, such as

Why should we stop [in] Europe? [...] We could expand this thing further on to [...] Japan [...] Chile [...] [the] United States [...] India [...]. There are so many places [where] this could be done (Finnish student 4, male).

Acting has traditionally been considered a discipline that requires physical and face-to-face contact sessions in classes. However, the experiences and the students' visions during the CO course seemed almost limitless for the prospects and the possibilities of intercultural disciplinary teaching cultures in universities (see e.g. Waters \& Brooks 2012). 
As Haworth and Conrad (1997, pp. 32-33) state, a supportive risk-taking environment is an important attribute of engagement, and the initiatives and the activeness of studying in a community are vital. When students feel safe enough, they dare to take risks in their learning and actions. Two factors highlighted this point in the experiments in the CO project. First, student actors have traditionally been quite reluctant to accept technological or virtual environments in their studies, mostly because of the cultural emphasis on bodily expression. However, during the CO project, the students moved rather easily from one technological environment to another and even introduced new ways of using personal social media to solve study-related problems. Second, the usually very daunting experience of throwing oneself into acting in a foreign language with a native speaker did not seem to be a long-term issue. The space appeared to provide each student with an opportunity to create a "homelike" thick place from where to build up the performance. The international co-operation did not happen in a strange cultural space but in a neutral place created by everyone's bodily presence.

\section{Learning Trajectories and Networks}

Each morning the students spent an hour performing in the virtual rehearsal space. The activities included group game sessions and lessons on Finnish folk dancing and singing. The students were prompted to take the lead in activities and were asked to bring up their ideas. The rest of each day was spent either working with smaller groups on the scene or rehearsing in both languages in their own Adobe Connect rooms or in Skype. As the process continued, the students became more familiar with the technology and more adventurous in pushing the boundaries of different platforms and spaces.

According to Leonardi (2011), "affordances and constraints are constructed in the space between human and material agencies" (p. 15). Affordance lead people to change their routines, opposite to constraints. The CO project offered certain specific affordances for students to create their own learning paths, which is important for understanding the learning space as a nexus of spaces (Leander et al. 2010). These trajectories are understood as comprising a dynamic and spatial plurality across the learning environment. The students from both countries also used informal spaces and resources for their learning and collaboration. Moving between these formal and informal platforms, connecting them and using them simultaneously made the social learning space more their "own", and moreover thicker, because the combination had no top-down organisation and no fixed pathways. When social space is not fixed and closed, trajectories in the space and learning are not uniform but can open different identity processes.

I feel that this was very beneficial for us for the future [...]; we have all these new people in our lives [who] live in another country [...] (Finnish student 1, female).

As Leander and his colleagues $(2010,342)$ write,

Learning which occurs across the permeable boundaries of formal and informal [in and out of the classroom], is posited as [a] connective, in between process; narrativization is a key means of stitching a life trajectory across time.

The experiences that students can acquire by connecting spaces together (with students abroad) open new worlds and possibilities for their cultural understanding and identity formation as well. Interestingly, this was seen as a positive process in the CO course too. 
It was a great way to bring people from other countries together [...] in the same room, really (Finnish student 2, female).

However, the experience was dialogical when meeting others who challenge the students' everyday learning context.

We shared our traditional dances and our working culture in theatre, and we combined those two (Finnish student 3, male).

Leander and colleagues (2010) encourage researchers to examine the mobilities of people moving through the learning spaces. This kind of social, situational and emotional connectedness seemed very real for the participants. Not only the telepresence technology, but also the social media that was used during the project with the students, brought them closer to one another. They pushed the classroom walls further by creating their own shared spaces after the rehearsals; they went to their local pubs in Tampere and Coventry and used web conferencing software just for hanging out. The CO Facebook group was filled with pictures of students spending time and talking to one another in the Adobe Connect virtual meeting room. As far as engagement is concerned, informal participation outside the curricular activities with the network of learners, located either in the on-campus or the off-campus environment, is almost as important as the formal one (cf. Krause 2007).

As one Finnish student pointed out, the course opened new possibilities for new projects for her own pathway to learn and make connections with students abroad. It could be interesting to follow up on how the course would affect the forthcoming choices of students in both universities, how they would build their own learning to be more mobile and how different cultural influences would shape their identities and acting. The CO project was just a start for a learning process that would jump from the static classroom to a nexus of places and a meeting point of different trajectories.

Telepresence offers new kinds of networking possibilities for learning, but ICT does not provide any automatic answer for learning networks. On the contrary, digital technology that is usually applied in teaching and learning is largely formalised and bounded in nature (Selwyn 2011); it does not automatically meet the needs of teachers and students. In the case of the CO project, the technology was not brought using the top-down approach but was selected to meet the special challenges of actor training.

However, technical problems existed as usual in digital environments. The teachers also admitted that it took time before all were comfortable with the environment.

From the perspective of learning networks, everything is moving and being transformed in social space. This movement helps students grasp space and make it their own. The space is not static and predetermined, but bodily movements, interaction and acting make the space without any technical restriction. During the project, the students learned to bring technology to their learning, especially to intensify their learning, as illustrated in this quote:

[...] at first, when I heard about the course, I was sceptical because I heard we were gonna use a lot of technology, and my experiences with technology have not always been good, [...] but it turned out [to] be [a] very successful and functional kit we used, so [...] that wasn't a problem at all. [...] we worked together because it was so intense (Finnish student 1, female). 
Technology brings new resources to the learning process and connects students and resources - in this case, in an intense way. In this context, intensity means that the students do not need to think about the technology, but it is domesticated, incorporated in everyday life and integrated into the patterns of spatial belonging.

At the same time, two cultures of how to learn and teach acting (Shakespeare) were networked to bring new perspectives to performance. The students used the networked space to move to another learning culture and interpretation of the play and learned to see acting and the play in a way that would not be possible in a local cultural space.

\section{Discussion}

In this article, we have mapped the landscape of studies on the spatial approach to HE by introducing some key concepts and reflecting their meanings and connections to the case example, showing the importance of spatial understanding and spatial experiments in HE. The meaning of pedagogic spaces in the HE context needs further empirical research, and hopefully, space-related aspects are becoming essential parts of curriculum work. Although these findings do not allow any larger scale generalisations to other HE disciplines, in the future it could be interesting to explore how fields other than acting would benefit from the telepresence settings.

Considering the meaning and importance of spatial understanding at a more general level, Edwards and Usher (2008, p. 76) emphasise the transition "from the fixed institution-based space of education to the more emergent terrain of learning." Instead of approaching teaching and learning from the traditional teacher-centred or student-centred perspective in $\mathrm{HE}$, we should examine the pedagogic spaces and the social possibilities that are either opened or excluded by the multiple interconnectedness of globalisation. Pedagogic spaces enable learning, not simply mediated by teachers, but also through fellow students, teaching assistants, technicians, the media, classroom artefacts, icons and texts (Edwards \& Usher 2008). This situation challenges individual practices of education and assessment, as well as insists that the pedagogic spaces of educational institutions cannot be isolated from the spaces of homes or workplaces.

In modern societies, homes, schools, universities and workplaces used to be rather closed and bounded spaces. However, they are now considered more open due to the changes in the idea of governmentality and the development of control mechanisms provided by the technology and networks. This means that new spaces and their relations are involved in pedagogy and the curriculum regardless of the nature of an academic discipline. As Edwards and Usher (2008) point out, the prior understanding that the ways of being in a place relate to the different meaning making processes highlights the importance of "spatialising pedagogies" and the focus on pedagogic spaces. Examining the pedagogic spaces of $\mathrm{CO}$ is an example of fulfilling the need for this focus in the field of educational studies. By understanding the dynamics and the interaction between the (geographic) self and space, it is possible to develop engaging environments for learning in $\mathrm{HE}$.

Middleton $(2018,5)$ argues that higher education's engagement with digital and social connectivity is largely superficial. "We have not properly understood what the digital context means for learning. In higher education, technology has had a reductionist rather than an expansive tendency: in general, we have not learnt how to experience knowledge differently, only how to deal with it differently." He sees that the challenge is to "reset the learning stage 
and develop a shared appreciation of the possibilities afforded by a physical-digital hybrid learning space."

The reflections from the CO course and particularly telepresence setting provided an interesting window to the process of creating a space for learning in HE. The way how both teachers and students described the bodily experiences of sensing the shared space is an example of the connections between space and engagement to studies. The learning space appeared as a nexus of spaces, comprising a dynamic and spatial plurality across the learning environments. Blurring boundaries between formal and informal spaces gave room for meaningful and embodied experiences - social, situational, and emotional connectedness with students in different places. The described learning trajectories, processes where virtual spaces were made "own" surprisingly fast, opened up new interesting questions about the role and meaning of digital environments in pedagogic practice.

\section{References}

Annala, J., Mäkinen, M., Svärd, P., Silius, K., \& Miilumäki, T. (2012). Social online environment in promoting engagement in higher education. Studies for the Learning Society, 2(2-3), 75-86. https://doi.org/10.2478/v10240-012-0007-0

Arias, S. (2010). Rethinking space: An outsider's view of the spatial turn. Geojournal, 75(1), 2941. doi:10.1007/s10708-010-9339-9

Brooks, R., Fuller, A., \& Waters, J. (2012). Changing spaces of education: An introduction. In R. Brooks, A. Fuller, \&J. Waters (Eds.), Changing spaces of education. New perspectives on the nature of learning (pp. 1-18). New York: Routledge.

Case, J. M. (2008). Alienation and engagement: Development of an alternative theoretical framework for understanding student learning. Higher Education, 55(3), 321-332.

Casey, E. (2001). Between geography and philosophy: What does it mean to be in the placeworld? Annals of the Association of American Geographers, 91(4), 683-693.

Dabbagh, N. \& Kitsanta, A. (2012) Personal Learning Environments, social media, and selfregulated learning: A natural formula for connecting formal and informal learning. The Internet and Higher Education, 15(1), 3-8. https://doi.org/10.1016/j.iheduc.2011.06.002

Edwards, R., \& Usher, R. (2008). Globalisation and pedagogy: Space, place, and identity (2nd ed.). London: Routledge.

Exeter, D., Ameratunga, S., Ratima, M., Morton, S., Dickson, M., Hsu, D. \& Jackson, R. (2010). Student engagement in very large classes: The teachers' perspective. Studies in Higher Education, 35(7), 761-775.

Hassenburg, A. (2009). Distance education versus the traditional classroom. Berkeley Scientific Journal, 13(1), 7-10. https://escholarship.org/uc/item/3859m52h

Haworth, J. \& Conrad, C. F. (1997). Emblems of quality in higher education: Developing and sustaining high-quality programs. Boston, MA: Allyn \& Bacon. 
Hu, S. \& Kuh, G. D. (2002). Being (dis)engaged in educationally purposeful activities: The influences of student and institutional characteristics. Research in Higher Education, 43(5), 555-575.

Ingold, T. (2011). Reply to David Howes. Social Anthropology, 19(3), 323-327.

Jamieson, P., Fisher, K., Gilding, T., Taylor, P. G., \& Trevitt, A. C. F. (2000). Place and space in the design of new learning environments. Higher Education Research \& Development, 19(2), 221-236.

Kahn, P. E. (2014). Theorizing student engagement in higher education. British Educational Research Journal, 40(6), 1005-1018.

Kahu, E. R. (2013). Framing student engagement in higher education. Studies in Higher Education. 38(5), 758-773.

Kanninen, M., Syrjä, T. \& Gorman, T. (2016). The Coriolanus Online project. In Proceedings of the 20th International Academic Mindtrek Conference: ACM, 457-459. http://dx.doi.org/10.1145/2994310.2994352

Kavanaugh, A., Carroll, J. M., Rosson, M. B., Zin, T. T., \& Reese, D. D. (2005). Community networks: Where offline communities meet online. Journal of Computer-Mediated Communication, 10(4), article 3. http://jcmc.indiana.edu/vol10/issue4/kavanaugh.html

Kipponen, A., \& Annala, J. (2016). Opintoihin kiinnittyminen opiskelijan elämismaailmassa. [Engagement in university studies in a student's lifeworld.] Kasvatus, 47(5), 406-418.

Krause, K-L. (2007). Social involvement and commuter students: The first-year student voice. Journal of the First Year Experience and Students in Transition, 19(1), 27-45.

Kuh, G. D. (2003). What we're learning about student engagement from NSSE: Benchmarks for effective educational practices. Change, 35 (2), 24-32.

Lea, M. R. \& Jones, S. (2010). Digital literacies in higher education: exploring textual and technological practice. Studies in Higher Education, 36(4), 377-393.

Leonardi, P. M. (2011) When flexible routines meet flexible technologies: affordance, constraint, and the imbrication of human and material agencies. MIS Quarterly, 35(1), 147167. Available at SSRN: https://ssrn.com/abstract $=1607718$

Leander, K., Phillips, N., \& Taylor, K. (2010). The changing social spaces of learning: Mapping new mobilities. Review of Research in Education, 34, 329-394.

Lefebvre, H. (2007). The production of space. Malden, Oxford, \& Carlton: Blackwell Publishing.

Leijon, M. (2016). Rum på campus i högre utbildning - didaktisk design och handlingsutrymme. [Space in a higher education campus.] Högre utbildning, 6(1), 3-20.

Malpas, J. E. (2007). Place and experience. A philosophical topography. Cambridge, New York, Melbourne, Madrid, Cape Town, Singapore, \& Sao Paulo: Cambridge University Press.

Massey, D. (1994). Space, place and gender. Cambridge: Polity Press.

Matthews, K. E., Andrews, V., \& Adams, P. (2011). Social learning spaces and student engagement. Higher Education Research and Development, 30(2), 105-120. 
Middleton, A. (2018). Reimagining spaces for learning in higher education. Macmillan Education.

Minocha, S. (2009). A case study-based investigation of students' experiences with social software tools. New Review of Hypermedia and Multimedia, 15(3), 245-265.

Montello, D. R., Grossner, K., \& Janelle, D. G. (2014). Space in mind: Concepts for spatial learning and education. Cambridge, Massachusetts; London, England: The MIT Press.

Muller, J. (2009). Forms of knowledge and curriculum coherence. Journal of Education and Work, 22(3), 205-226. doi:10.1080/13639080902957905

Muller, J., \& Young, M. (2014). Disciplines, skills and the university. Higher Education, 67(2), 127-140. doi:10.1007/s10734-013-9646-4

Mäkinen, M., Linden, J., Annala, J., \& Wiseman, A. (2018). Millennial generation preservice teachers inspiring the design of teacher education. European Journal of Teacher Education, 41(3), 343-359. doi:10.1080/02619768.2018.1448776

Nicol, D. J., \& Boyle, J. T. (2003). Peer instruction versus class-wide discussion in large classes: A comparison of two interaction methods in the wired classroom. Studies in Higher Education, 28(4), 457-473. doi:10.1080/0307507032000122297

Pallant, A., McIntyre, C., \& Stephens, A. L. (2016). Transforming undergraduate research opportunities using telepresence. Journal of Geoscience Education, 64(2), 138-146. http://dx.doi.org/10.5408/15-118.1

Pink, S., \& Hjorth, L. (2012). Emplaced cartographies: Reconceptualising camera phone practices in an age of locative media. Media International Australia, 145, 145-155.

Selwyn, N. (2011). Schools and schooling in the digital age: A critical analysis. New York: Routledge.

Silius, K. , Miilumäki, T., Huhtamäki, J., Tebest, T., Meriläinen, J. \& Pohjolainen, P. (2010). Students' Motivations for Social Media Enhanced Studying and Learning. Knowledge Management \& E-Learning: An International Journal (KM\&EL), the Special Issue on "Technology Enhanced Learning" 2(1).

Smith, R., Killgore, W.D.S. \& Lane, R.D. (2018). The Structure of Emotional Experience and Its Relation to Trait Emotional Awareness: A Theoretical Review. Emotion 18(5), 670-692. https://oce.ovid.com/article/00130470-201808000-00005/HTML

Syrjä, T. (2007). Vieras kieli suussa. Vieraalla kielellä näyttelemisen ulottuvuuksia näyttelijäopiskelijan äänessä, puheessa ja kehossa. [A strange tongue in the mouth. The dimensions of acting in a foreign language in the student actor's voice, speech and body.] Department of Acting, University of Tampere. Tampere: Tampere University Press. Retrieved from http://tampub.uta.fi/handle/10024/67761

Temple, P. (2008). Learning Spaces in Higher Education: An Under-Researched Topic. London Review of Education, 6(3), 229-241. doi:10.1080/14748460802489363

Temple, P. (2018). Space, place and institutional effectiveness in higher education. Policy Reviews in Higher Education, 2(2), 133. doi:10.1080/23322969.2018.1442243 
Waters, J., \& Brooks, R. (2012). Transnational spaces, international students. Emergent perspectives on educational mobilities. In R. Brooks, A. Fuller, \& J. Waters (Eds.), Changing spaces of education. New perspectives on the nature of learning (pp. 21-38). New York: Routledge.

Weaver-Hightower, M. B. (2003). Crossing the divide: Bridging the disjunctures between theoretically oriented and practice-oriented literature about masculinity and boys at school. Gender and Education, 15(4), 407-423.

Zepke, N., \& Leach, L. (2010). Improving student engagement: Ten proposals for action. Active Learning in Higher Education, 11(3), 167-177.

Zhao, C-M. \& Kuh, G. D. (2004). Adding value: Learning communities and student engagement. Research in Higher Education, 45(2), 115-138. 